\title{
Sobre Como e Por Que Construir, (Re)Construir e Avaliar Projetos Terapêuticos nos Centros de Atenção Psicossocial (CAPS)
}

\author{
Verônica Sanduvette ${ }^{1}$ \\ Doutora em Psicologia, IP-USP
}

\begin{abstract}
Os trabalhadores implicados na Reforma Psiquiátrica Brasileira, predominantemente mulheres, têm enfrentado o desafio de transformar os modos de assistir às pessoas acometidas por transtornos mentais. Nessa empreitada, é necessário contar com operadores para a reorganização do trabalho, passando-se da realização de tarefas para projetos, e da multidisciplinaridade para a interdisciplinaridade. Com esse fim, temse aplicado um método de análise e intervenção baseado no registro do conhecimento contextual dos membros das equipes, a partir do qual são construídas "fotografias" dos serviços prestados, transformadas a seguir em instrumentos de observação e avaliação psicossocial. As avaliações constituem um eixo à gestão da informação, tida como fundamental para as práticas em Saúde Coletiva na Saúde Pública. Salienta-se a importância da reformulação das ações terapêuticas através da sua reinvenção, no cotidiano dos serviços comunitários afinados com o Modelo de Atenção e Reabilitação Psicossocial preconizado pelo Ministério da Saúde.
\end{abstract}

Descritores: Reforma Psiquiátrica (Brasil). Reabilitação psicossocial. Organização do trabalho. Etnometodologia.

Interdisciplinaridade. Saúde pública.

Há muitos modos de observar e apreender a realidade.

Roland Barthes lembrou que a Câmara Clara ajuda a desenhá-la.

1 Consultora e assessora para a (re)organização de serviços em Saúde Mental nas redes de assistência em Saúde Pública. Membro do LASAMEC (Laboratório de Saúde Mental Coletiva), Faculdade de Saúde Pública, USP-SP. Endereço eletrônico: sanduvete@ uol.com.br 


\section{Verônica Sanduvette}

$\mathrm{U}^{\mathrm{s}}$ ma forma de promover a discussão sobre a construção, a reconstrução e a avaliação de projetos terapêuticos é questionar a identidade dos próprios CAPS, no ambiente de transição em que se encontram, neste momento histórico da sua expansão. Se em janeiro de 1992 menos de duas dezenas de serviços eram apontados como modelares, em dezembro de 2006 havia 1011 cadastrados em todo o Brasil (Ministério da Saúde, 2007). O que são os CAPS, os Centros de Atenção Psicossocial? Sabe-se que ao primeiro - o CAPS Prof. Luiz da Rocha Cerqueira, criado em 1987 por trabalhadores da Secretaria de Estado da Saúde na cidade de São Paulo, na rua Itapeva, onde ainda se encontra - seguiram-se os cinco NAPS de Santos ("Núcleos" em vez de "Centros", com a diferença primordial de funcionarem 24 horas), implantados sucessivamente entre 1989 e 1994. Essas experiências multiplicaram-se, no país, por meio do investimento político dos trabalhadores de Saúde Mental junto aos gestores públicos. A Rede de Alternativas à Psiquiatria, iniciativa internacional compartilhada na década de 1980 por alguns dos mais expressivos gestores e pesquisadores brasileiros em Saúde Mental da atualidade, e a Luta Antimanicomial, iniciada em 1987, constituíram-se como movimentos em defesa do principal direito das pessoas acometidas por transtornos mentais: o de serem tratados junto às suas famílias e comunidades, entendendo-se que Tratar não é Trancar (Conselho Federal de Psicologia, 1997). Permanecer no hospital psiquiátrico por meses ou dezenas de anos era, até então, a prescrição médica prevalente.

A Declaração de Caracas (1990/2004), da qual o Brasil foi signatário, estabeleceu a política e as diretrizes, em acordo com a tendência mundial de "atendimento comunitário, descentralizado, participativo, integral, contínuo e preventivo" preconizado pela Organização Mundial de Saúde (OMS). Essa tendência permanece atual. De acordo com Saraceno (2006), diretor do departamento de Saúde Mental e Abuso de Substâncias da OMS. Para enfrentar os desafios da globalização, os gestores precisam garantir o acesso ao tratamento, a qualidade da assistência e o respeito aos direitos humanos; para isso, é necessário que possam desenvolver e praticar políticas coerentes e abrangentes, investindo em intervenções efetivas na atenção primária, dando suporte para que as próprias comunidades se fortaleçam e contribuindo com o desenvolvimento dos profissionais da Saúde Mental, inclusive no que tange ao uso de sistemas de informação e à realização de pesquisas. No Brasil, desde 1992, a 
Sobre Como e Por Que Construir, (Re)Construir e Avaliar Projetos Terapêticos...

publicação da Portaria ministerial SNAS n ${ }^{\circ} 224 / 92$ impulsionou a implantação de equipamentos extra-hospitalares, dimensionando os serviços e as equipes necessárias para o seu funcionamento, de acordo com os princípios do Sistema Único de Saúde (SUS) - universalidade, hierarquização, regionalização e integralidade das ações - a serem praticados pela rede de assistência em saúde, sob responsabilidade dos gestores locais. Com a aprovação da Lei ${ }^{\circ}$ 10.216/01 e a publicação da Portaria GM n 336/02, os CAPS foram ratificados como equipamentos substitutivos ao modelo psiquiátrico hospitalocêntrico tradicional, e como reguladores da rede de assistência em Saúde Mental para psicóticos e neuróticos graves, estendendo-se a crianças e adolescentes (CAPSi II) e a dependentes de álcool e outras drogas (CAPSad II). A política de assistência aos dependentes de álcool e outras drogas reitera igualmente a necessidade de tratar essas pessoas sem excluí-las da comunidade, ou seja, sem interná-las além do período mínimo necessário para atender à situação clínica, quando grave, derivada da abstinência ou da dependência. Para tanto foi publicada, em setembro de 2005, a Portaria GM1612/05, que preconiza a criação de leitos em hospital geral, onde deve ocorrer o atendimento à crise, após o que o usuário deve ser assistido na rede de saúde local, sob a responsabilidade dos CAPSad.

Levando em conta os vinte anos de vivências dos hoje milhares de trabalhadores(as) que praticam a defesa da assistência e do respeito à subjetividade e aos direitos humanos das pessoas acometidas por transtornos mentais, é particularmente a estes(as) que se endereçam as considerações seguintes. Neste texto foram escolhidos três aportes, e afirmações decorrentes, a partir dos quais se pretende provocar as posições de quem está mergulhado na travessia de construção da rede extra-hospitalar de atenção à Saúde Mental, em consonância com o Modelo de Atenção e Reabilitação Psicossocial (Pitta, 1996). Como norteadores, consideram-se os conceitos de acolhimento, vínculo e responsabilização, defendidos por Merhy, Magalhães Junior, Rimoli, Franco e Bueno (2004), sanitaristas que vêm repensando o trabalho em Saúde Pública, no Brasil, há pelo menos duas décadas. Esses conceitos foram reafirmados pela Dra. Ana Maria Fernandes Pitta, responsável pela organização dos grupos de trabalho relacionados com o cuidado cotidiano nos CAPS, no I Congresso de Centros de Atenção Psicossocial, realizado em São Paulo, em junho de 2004, no qual foi apresentado o método que constitui o segundo aporte des- 


\section{Verônica Sanduvette}

te texto. Aqui se declara a filiação à proposta sanitarista como condição sine qua non da clínica em Saúde Mental: sem franquear o acesso, eliminando as listas de espera e estendendo a atenção à população, não se faz saúde coletiva; sem acolhimento, não há possibilidade de vínculo; sem vínculo, não há como desenvolver a responsabilização também na pessoa que é assistida. Para mais além, como um dos fundamentos da prática a ser descrita, concorda-se com Ecléia Bosi, para quem "tudo começa numa afinidade, numa simpatia do sujeito da percepção e da ação pelo seu objeto" (Bosi, 2004, p. 125); e que "essa atitude não é uma técnica, é uma conversão" (pp. 125-126).

Aos três aportes. Em primeiro lugar, considere-se que os Centros de Atenção Psicossocial são organizações de trabalho: neles estão trabalhadores, ou, melhor dizendo, trabalhadoras. Ao ser conferida a audiência do I Congresso de Centros de Atenção Psicossocial, as mulheres eram a maioria, em torno de $80 \%$ dos presentes. As mulheres são maioria na Saúde e na Educação. Segundo o jornal São Paulo Saúde (2004), entre os 72.600 funcionários da Secretaria de Saúde do Estado de São Paulo, as 51.272 mulheres correspondiam a $70 \%$ do total. No âmbito da Psicologia, de acordo com pesquisa realizada pelo Conselho Federal de Psicologia para avaliar o perfil dos psicólogos brasileiros, 92,2\% dos entrevistados eram do sexo feminino (Jornal do Federal, maio/2006). Como trabalhadoras(es), na Saúde Mental, estão sendo convocadas(os) a uma dupla missão redentora: redimir a loucura, a desrazão, excluída nos últimos 300 anos; e consolidar, a curtíssimo prazo, novos modos de tratá-la. No cumprimento dessa missão, é preciso confrontar, entre outros interesses adversários, o recrudescimento da psiquiatria biológica - a serviço de uma lógica local a que se alia, a da indústria farmacêutica - e o individualismo da sociedade contemporânea, na qual tem se mostrado necessário "professar" a inclusão das diferenças humanas, físicas e/ou mentais, étnicas e/ou culturais, bem como a das escolhas subjetivas, de opção sexual, entre outras.

Entendendo-se os CAPS como organizações, é importante compreender e verificar como o trabalho é conduzido, se através de tarefas ou de projetos (Malvezzi, 1994). Tarefas podem ser mais ou menos formatadas, mais ou menos controladas, mais ou menos extenuantes. Em comum, tem-se a repetição: do apertar o parafuso ao atendimento psicológico com duração limitada e em intervalos predeterminados, o rigor técnico e a norma burocrática se colocam acima da pessoa que requer a assistência. Repetir tarefas remete o trabalho ao 
Sobre Como e Por Que Construir, (Re)Construir e Avaliar Projetos Terapêticos...

conceito de tripalium, tortura, castigo para ganhar a vida, com o suor do próprio rosto. Ao trabalhar executando tarefas repetitivas, o que se vende em troca do salário é o tempo (as 6 ou 8 horas por dia, cinco dias por semana, o mês); o produto pode escapar e ser apropriado por terceiros: o senhor da escravidão, o dono do capital, o gestor burocrata (Enriquez, 1997a) ou, ainda, os detratores da Reforma Psiquiátrica Brasileira. Acomodar-se nas rotinas, repetindo tarefas, pode redundar no que se vê com os pacientes que permanecem dias, semanas, meses ou anos sentados no mesmo sofá, vendo o mesmo programa de televisão, convidados a comparecer ao grupo com a psicóloga (os "resistentes" não vão), às vezes indo à mesma oficina de reciclagem de materiais... Acomodar-se nas rotinas, repetindo tarefas, pode ser a manutenção dos mesmos e únicos procedimentos de avaliação clínica médico-centrados, a prescrição farmacológica contendo e definindo o espaço de tratamento, as ações dos outros profissionais permanecendo periféricas... Acomodar-se nas rotinas pode também significar o estabelecimento de relações de familiaridade excessiva entre alguns pacientes e alguns trabalhadores(as), quasi irmanados, o que remete ao sucesso de alguns poucos (pacientes, e às vezes, trabalhadores), banalizandose as interações (terapêuticas) em detrimento do conjunto da população de um determinado serviço, ou dos CAPS em geral. O assim permanecer nos CAPS lembra o entretenimento, o ter dentro assinalado por Saraceno (1999, p. 70); eventos sentinela, sinalizam o tempo que passa, mas pouco altera, pouco produz, e o que produz escapa dos(as) trabalhadores(as).

A palavra projeto, do latim projicere, lançar para adiante, torna-se substantiva quando significa plano, intento, e mais, desígnio (designar, por sua vez, quer dizer dar a conhecer, nomear, indicar, fixar, qualificar...) (Ferreira, 1975, p. 455). Ao planejar e realizar projetos, a idéia modela a ação, a ação enseja a reflexão sobre o realizado, e, se houver condições de auto-regulação do tempo necessário para idealizar e/ou remodelar a construção (Livet, 1981), há uma certa autonomia do trabalhador, o qual, embora permaneça vendendo força de trabalho, ainda assim pode responsabilizar-se, porque precisam ser buscadas e sustentadas as respostas aos problemas que se colocam. Esse modo de trabalhar pode vir a ser produtor de mundanidade (Arendt, 1991), da criação que eventualmente transcende o criador, permanecendo na cultura; assim foi, na Saúde Mental, de Pinel a Basaglia, de Ulisses Pernambucano e Nise da Silveira a Luís Cerqueira, para citar as pessoas mais representativas, sem detrimento, no en- 


\section{Verônica Sanduvette}

tanto, dos outros tantos que nas últimas três décadas têm se dedicado a mudar a forma, o conteúdo e a configuração política da assistência em Saúde Mental.

Desse primeiro aporte, decorrem as primeiras afirmações: nos CAPS se está trabalhando numa organização. A organização CAPS, um equipamento público do SUS, presta serviços: atende e assiste pessoas acometidas por psicoses e neuroses graves, ou ainda dependentes de álcool e outras drogas. A qualidade nessa prestação de serviços supõe a evolução do paciente na direção da promoção da sua saúde e da sua cidadania; supõe resolutividade, que se entende como eficiência mais eficácia nas intervenções. Não basta, portanto, estar dentro do CAPS, por algumas horas diárias, repetindo tarefas, às vezes até bem eficientes, mas ineficazes se não implicam em evolução psicossocial dos pacientes; é necessário elaborar projetos, definir e publicar planos de ação, com e para a equipe, com e para as pessoas que são o alvo da assistência. Na Saúde Mental, os projetos para cada paciente são chamados de projetos terapêuticos individuais, "PTIs"; ao traçá-los, se está contribuindo com o "desenho" do futuro das pessoas assistidas. Nesses casos, a responsabilidade do(a) trabalhador(a) é inevitável: "responsabilidade" quer dizer "capacidade de dar respostas". No trabalho organizado por projetos, é fundamental tornar-se capaz de dar respostas, designando (nomeando, indicando, qualificando) as mudanças desejáveis. Sempre será necessário escolher entre as ações possíveis, na atenção a cada usuário, em cada momento da sua história, situação ou condição; comprometer-se, enfim. Entretanto, a passagem do mero escolher, da responsabilidade como capacidade de dar respostas, para a responsabilização implica em mobilizar a própria subjetividade, fazendo do julgamento ético a base das escolhas (Arendt, 2004).

Mais um aporte, o segundo: nos CAPS se pratica a atenção e reabilitação psicossocial. Segundo Saraceno (1999), a Atenção e Reabilitação Psicossocial trata-se de uma "prática à espera de teoria", a qual questiona o modelo clínico tradicional porque este não tem "beneficiado de maneira substantiva os pacientes"; uma prática que "pôs no seu centro uma idéia bastante interessante e bastante estimulante que é a negociação.” (Saraceno, 1999, pp. 150-151)

Precisamos pensar que as complexas e articuladas práticas, que caracterizaram os últimos 25 anos da psiquiatria inovadora em todo o mundo, necessitam urgentemente de referência teóricas.... Penso que as referências que 
Sobre Como e Por Que Construir, (Re)Construir e Avaliar Projetos Terapêticos...

devemos construir, e este é o desafio dos próximos 20 anos, está exatamente na reconstrução, também, de uma palavra que substitua a palavra clínica, que nos ajude a definir o processo de construção ou reconstrução de um campo de encontro entre curantes e clientes, médicos e pacientes, usuários e profissionais... Um campo onde se realize este encontro e que, ao ser realizado, produza senso, sentido" (Saraceno, 1999, pp. 152-153).

Considerando a Atenção Psicossocial como alternativa à clínica tradicional, são relevantes as maneiras através das quais as pessoas interagem, e a maneira como compreendem a realidade institucional na qual se dá a assistência em Saúde Mental. Nos moldes como tem sido praticada, a assistência transcorre intermediada por diversas atividades - recreativas, ocupacionais, culturais -, as quais, em princípio, podem tornar-se dispositivos para delimitar, multiplicando, campos de encontro, no coletivo que pode emergir (Oury, 1986). Para além de campo de encontro, espaço de vida psicológico (Lewin, 1965), também pode se configurar um espaço de saber, "argumento no qual estamos inseridos... que tem múltiplas faces e materialidades, que acontecem em muitos lugares diferentes" (Spink, 2003, p. 28). Nestes os trabalhadores são, como os usuários, membros da mesma comunidade: de ação, interação, conhecimento e intersubjetividade, permeada por diferenças sociais, étnicas e culturais, e, também, pelos modos de gestão do trabalho organizado.

Como serviços substitutivos à internação hospitalar, os CAPS são instituições de continência e assistência para a população acometida por transtornos mentais graves. Isso significa que, em algumas ocasiões de emergência de crises, o tratamento pode ser intensivo, com os pacientes comparecendo diariamente e permanecendo durante todo o dia nas dependências do serviço, fazendo as refeições, e eventualmente pernoitando, quando se trata de CAPS do tipo III. O tratamento supõe a evolução para um atendimento semi-intensivo (de um período ao dia, ou de alguns períodos por semana) e para não intensivo - o paciente ficando referenciado no CAPS, mas inserido na comunidade e atendido na rede básica de saúde. A convivência entre os pacientes e os profissionais não garante, no entanto, que as equipes multiprofissionais consigam superar as dificuldades para praticar a desejada interdisciplinaridade nas suas ações, decorrendo com freqüência que a assistência permaneça centrada no modelo clínico de assistência individual. Os espaços físicos delimitados para as funções pro- 


\section{Verônica Sanduvette}

fissionais específicas denunciam a clínica tradicional (Onocko Campos, 2001) e a cisão entre as ações: a sala do psiquiatra (onde ocorrem as consultas), a do psicólogo, para as psicoterapias (individuais ou grupais), as oficinas de terapia ocupacional, o posto de enfermagem, a assistência social também separada. O dispositivo de integração mais usado pelas equipes é a reunião de discussão de casos, mas os profissionais não costumam fazer uso de protocolos, instrumentos ou procedimentos de observação que facilitem a interlocução entre as diversas categorias, o planejamento e a avaliação das ações; além disso, em geral, não dispõem de recursos para registrar e gerenciar informações necessárias para ações em Saúde Coletiva, relacionadas com o atendimento das populações. Quando os recursos de informatização existem, os profissionais de saúde em geral não se inclinam ou não se autorizam a computar dados. Os computadores apenas substituem as máquinas de escrever para atender às burocracias, e usá-los compete, via de regra, aos assistentes administrativos. A falta de instrumentos de observação e de registros informatizados dificulta a transparência, a exposição e a circulação de conhecimento e saberes, que são fundamentais para a constituição da interdisciplinaridade, tanto no sentido operacional, de ampliação e troca de informações, quanto no sentido mais amplo, de opção pela teoria da complexidade (Morin, 1990, 1996, 2003), pelo paradigma pós-disciplinar (Almeida Filho, 2005) e pelo desenvolvimento de atitudes e de práticas (Alvarenga, Sommerman \& Alvares, 2005; Castiels, 1999; Sommerman, 2006), particularmente na Saúde Mental (Vasconcelos, 1997).

Como objeto de trabalho, a atenção psicossocial se dá no dia-a-dia da interação e da convivência humana. O que se conhece do cotidiano dos relacionamentos, no entanto, é uma construção social. O conhecimento é socialmente construído através da permanente produção, reprodução e reconhecimento das ações e estruturas sociais, conferindo-se à "realidade" o estatuto de ordenada e previsível, conforme referenciais construcionistas da Psicologia Social (Spink, 1999), da Sociologia do Conhecimento (Berger \& Luckmann, 1996) e, particularmente, da Etnometodologia (Garfinkel, 1984). Segundo Schütz (1976), quando as pessoas interagem, na vida diária, há uma suspensão geral da dúvi$d a$ de que as coisas poderiam ser diferentes do que parecem, e a objetividade das situações é dada como ponto pacífico, através de sínteses de identificação, no interior de uma estrutura de familiaridade e pré-convivência, o que a torna tipificada. A relação intersubjetiva se dá através de processo ativo, no qual 
Sobre Como e Por Que Construir, (Re)Construir e Avaliar Projetos Terapêticos...

os participantes admitem uma reciprocidade de perspectivas. Resulta que o conhecimento do senso comum, no cotidiano, seja baseado em suposições, conjeturas, pré-conceitos, à moda de uma colcha de retalhos (Heritage, 1996). Como em qualquer outro agrupamento humano em que o conhecimento comum tenha se estabelecido através das interações sociais recorrentes, tipificando-se, as rotinas de trabalho nos CAPS podem perder visibilidade, tornar-se opacas, embaçando a visão da paisagem para as pessoas que estão no mesmo barco, sejam profissionais ou pacientes. Desses referenciais decorre que uma dentre as várias formas de lidar com a atenção psicossocial dentro dos CAPS, entendidos como organizações de trabalho, seja questionar, dar visibilidade e ampliar o conhecimento dos(as) trabalhadores(as) sobre o seu cotidiano. Para observar, analisar, fazer julgamentos, tomar decisões e planejar, traçando planos de ação, projetos, precisa-se de instrumentos para focar e registrar as relações que fazem e instituem o dia-a-dia da assistência.

Com base nessas premissas, o levantamento do conhecimento da comunidade sobre a sua "realidade" tem sido usado como referência e como dispositivo gerador de informação para implementar a inter(trans)disciplinar idade e a qualidade do trabalho em Saúde. Desde 1993, venho desenvolvendo e praticando um conjunto de procedimentos, um método, para ajudar a construir, (re)construir e avaliar projetos terapêuticos baseados no cotidiano "conhecido" (Sanduvette, 2003). Considerando as interações sociais como indiciadas na linguagem (Garfinkel, 1984), relatar o cotidiano pode ser uma forma de capturá-lo. Nas intervenções feitas junto aos serviços, na forma de assessoria, pede-se a todos os trabalhadores, mas também a alguns usuários, que relatem tudo que os pacientes fazem, enquanto permanecem no CAPS (ou em outro tipo de serviço da rede de assistência, seja hospital, ambulatório, Unidade Básica de Saúde, equipada ou não com a Estratégia de Saúde da Família). A experiência de recordar, relatando, o que acontece diariamente no e durante o serviço, é em si mesma esclarecedora, e pode ser feita por qualquer profissional que esteja lendo este texto. Caso o leitor seja um trabalhador de Saúde, sugiro fazer uma pausa nesta leitura, pegar papel e lápis e dispor-se a redigir uma lista respondendo à seguinte pergunta: o que faz o paciente, com quem, onde, como?

Se o exercício foi feito, vamos conferi-lo. A primeira tendência observada é a de ater-se às ações previstas institucionalmente, focando no que o pro- 


\section{Verônica Sanduvette}

fissional faz, ou deveria fazer, segundo as prescrições estabelecidas no serviço. Diz-se com freqüência que o paciente participa de grupos, passa por consultas, recebe medicação, faz as refeições, o que, em verdade, descreve a rotina prevista. Muito menos frequiente é a descrição da conduta dos usuários, nas suas muitas variantes, ditas normais ou consideradas como psicopatológicas. Mais: depois de um certo número de itens, usualmente pequeno, a memória deixa a desejar, e a dificuldade para lembrar o que se "vê" e faz durante o tempo em que se está trabalhando na assistência, aquilo que se faz todos os dias, começa a produzir estranhamento. Essa dificuldade também se aplica a outros setores de trabalho, em organizações públicas ou privadas, bem como à vida cotidiana em geral. Registram-se limites na apreensão da "realidade", reiteradamente demonstrados, ao longo das minhas sucessivas interferências nos serviços de assistência à Saúde, nos últimos dez anos. Nas cerca de duas mil entrevistas realizadas com os trabalhadores, inclusive com os de nível universitário, o número de ações das pessoas que usam os serviços, tal como "lembradas" pelos entrevistados, sempre foi restrito, nunca excedendo duas dezenas individualmente, nunca ultrapassando a média de treze para o conjunto de entrevistados. Essas afirmações podem ser verificadas em Sanduvette (2003, p. 93). A indução necessária é que esses limites para apreender as ações cotidianas fazem parte da natureza humana, e remetem aos modos de conhecer e viver em grupos. $\mathrm{O}$ fato de haver dificuldades para indicar verbalmente o alcance das práticas da vida diária não impede reconhecer que sempre há uma lógica local, uma metodologia implícita no senso comum, a qual é compartilhada e sustentada na convivência do grupo, no que não é ou não precisa ser dito, através do exercício de rotinas.

Utilizando o procedimento de Análise de Conteúdo (Bardin, 1977), as respostas fornecidas são codificadas e computadas de acordo com categorias descritivas, mantendo-se a fidelidade aos enunciados originais. Com essas categorias, obtém-se uma relação de ações, as quais são organizadas em conjuntos temáticos. Registrar a opinião, o ponto de vista, ou seja, as perspectivas de cada um, e alinhavá-las com as de todos os envolvidos no serviço, resulta em "fotografias", em instantâneos a refletir a "realidade" conhecida ${ }^{2}$, costurandose a colcha de retalhos que constitui o conhecimento do grupo de pessoas

2 A idéia de "fotografia" remete à Câmara Clara: há um trabalho de "desenho" para compor a imagem do conhecimento do cotidiano dado pelos seus agentes, caracterizando a responsabilidade da autora, e o método descrito funciona como refletor. 
Sobre Como e Por Que Construir, (Re)Construir e Avaliar Projetos Terapêticos...

que freqüenta o serviço. Algumas ações são muito mencionadas (em geral as institucionais ou institucionalizadas); outras são lembradas apenas por um entre os entrevistados (em geral as relacionadas ao efetivo comportamento do paciente). A estratégia tem ajudado os profissionais a refletirem sobre o seu trabalho, promovendo modificações na assistência, através da aplicação dos procedimentos relatados a seguir.

A exposição pública das "fotografias" construídas induz as equipes à reflexão sobre o próprio trabalho, o que contribui para ampliar a visão e o conhecimento dos participantes. Mas o método de interferência no conhecimento local inclui transformar as fotografias em instrumentos de observação. Com elas são construídos protocolos para identificar a posição de cada pessoa, na sua singularidade, e da população atendida, no conjunto de possibilidades ou, melhor dizendo, potencialidades (Castiels, 1999), que fica evidenciado nas fotografias. A partir desse momento, essa intervenção instrumentaliza as equipes, que passam a dispor do protocolo para observar os pacientes, gerando informações sobre cada um e sobre a população assistida. Ao mesmo tempo, os trabalhadores são capacitados para registrar as observações feitas em arquivos computadorizados, os quais passam a ser usados como eixos para a gestão do conhecimento sobre os diferenciais da população assistida.

A subseqüente consolidação das informações às vezes surpreende, às vezes espanta, e contribui para romper com o senso comum estabelecido, permitindo a sua recriação. Revelam-se indicadores de qualidade dos serviços prestados, baseados nos dados encontrados para todos os usuários (Sanduvette, 2001). O processo permite elaborar diagnósticos psicossociais, que concebo como o conjunto de possibilidades (e necessidades) dos usuários, contextualizado no que pensam os funcionários (mas também os usuários) sobre as interações que constituem o CAPS. Sem detrimento das avaliações psiquiátricas tradicionais, e de outras avaliações específicas conduzidas pelas diferentes categorias profissionais, igualmente necessárias e complementares, os diagnósticos psicossociais permitem fundar e orientar o trabalho organizado por projetos. Porque são baseados nas estratégias do fazer cotidiano, acessíveis e disponíveis para todos, profissionais e usuários, constituem-se como operadores para a interdisciplinaridade, criando condições para que os membros das equipes ampliem o campo de ação para além daquele que é dado pelas disciplinas das suas respectivas formações acadêmicas, dispondo de eixo 


\section{Verônica Sanduvette}

comum concreto (as observações), podendo responsabilizar-se coletivamente pelos projetos institucionais e, com o usuário, pelos projetos terapêuticos individuais. Porque baseados nos potenciais e necessidades observados nos pacientes, os diagnósticos psicossociais permitem elaborar prognósticos diferenciados e passíveis de manejo e intervenção, para além do exame clínico e das classificações psiquiátricas usuais.

A apropriação dos dois aportes fornecidos - considerar os CAPS na instância de organização de trabalho e reconhecer a constante reinvenção do cotidiano psicossocial (e do conhecimento sobre esse cotidiano) - permite encaminhar o terceiro aporte: é necessário administrar os CAPS e gerenciá-los avaliando permanentemente os usuários e os serviços prestados. A construção, reconstrução e/ou avaliação dos projetos não pode prescindir da gestão da informação, e é desejável que esteja associada à gestão do conhecimento (Malvezzi, 1996). Entende-se que a avaliação é a base para qualquer projeto (inclusive os terapêuticos), e que, para gerenciar, é necessário avaliar, construindo cartografias dos pontos visualizados e das rotas escolhidas. Considera-se possível e desejável associar a avaliação à intervenção, e vice-versa. Ancorando-se no cotidiano socialmente construído e assim (re)conhecido, os diagnósticos psicossociais, recorrentemente realizados, podem se transformar em eixos de gestão do trabalho por projetos, em torno dos quais se congregarão o investimento interdisciplinar das equipes e a promoção da saúde coletiva. Conhecer o cotidiano pelo prisma dos seus agentes torna a avaliação psicossocial participativa e inclusiva, atendendo-se aos princípios da quarta geração da avaliação, conforme Guba e Lincoln (1989). Avaliador e avaliado sendo membros da mesma comunidade de sentido, facilita-se o acolhimento e o vínculo. Tomar o conhecimento do cotidiano como ponto (porto) de partida da gestão constitui, portanto, uma forma de "gerenciamento participativo autosustentável" (Sanduvette, 2003, p. 138). A maneira como se avalia sempre está associada a um determinado modo de gestão (com seus pressupostos políticoideológicos): por isso, também é necessário identificar o modo de gestão, e assumi-lo, considerando que apenas na gestão participativa (Chanlat, 1997; Enriquez, 1997a) está previsto espaço para o exercício da autonomia do trabalhador, a autonomia que permite a realização de projetos, e que implica, necessariamente, na responsabilidade. A constituição dos CAPS como estruturas organizacionais de pequeno porte, simples, que exercem a horizontalidade de 
Sobre Como e Por Que Construir, (Re)Construir e Avaliar Projetos Terapêticos...

poder nas decisões sobre as condutas com os pacientes, as quais devem ser tomadas pela equipe multiprofissional, os caracteriza, desde a sua origem e idealização, como sistemas de gestão participativa, facilitadores do trabalho organizado por projetos.

Finalmente, ao trabalho: como construir e (re)construir projetos? Aceitos os aportes anteriores, com base no diagnóstico psicossocial entendido como o conjunto de possibilidades e necessidades dos usuários, contextualizadas no cotidiano, as equipes dos CAPS podem investir o seu imaginário motor (Enriquez,1997b): deixar-se levar pela imaginação, viabilizar mudanças no processo que depende da improvisação coletiva, que explora possibilidades da própria aprendizagem como condição para a emergência do trabalho criativo. "O imaginário está do lado do projeto: é ele que se apresenta como a raiz das utopias, das práticas sociais inovadoras" Enriquez,1997b, p.36). O cuidado, aqui, é o de não se deixar levar, ao contrário, pelo imaginário enganador (p. 35) das "missões" impossíveis e narcisistas, ou, ainda, dos pactos denegatórios (Käes,1991, citado por Onocko Campos, 2001) que podem tirar o norte justamente daqueles que estão navegando na rota da necessária implantação da rede substitutiva de atenção à Saúde Mental. O desafio está em avançar na construção de campos de encontro, reconhecendo os argumentos onde estamos inseridos. Alguns autores parecem estar mais próximos disso, ao propor elementos de clínica institucional e comunitária, espaços coletivos e ambientes transicionais pensados para as psicoses e neuroses graves; entre eles, Jean Oury e Donald Winnicott, os quais se podem reencontrar nas leituras feitas por Verztman e Gutman (2001). Na prática dessa clínica psicossocial possível, nos CAPS como sistemas organizados, trata-se de usar uma bússola dialética: das mudanças viabilizadas (Weick, 1989), construídas coletivamente com base nos diagnósticos psicossociais, devem decorrer transformações no cotidiano, que demandarão outros investimentos para (re)conhecê-lo, dos quais podem emergir novos diagnósticos psicossociais, subseqüentes avaliações, ainda outros projetos e assim sucessivamente. Trabalhar dessa maneira tem oferecido evidências da transformação do qualitativo (do conhecimento existente) em quantitativo (das avaliações) e, novamente, em outro qualitativo (o da assistência modificada).

Uma última afirmação refere-se ao fato de estarmos todos à mercê das dimensões do real: possíveis e impossíveis, necessários e contingentes (Piaget, 


\title{
Verônica Sanduvette
}

1986). Sempre estaremos, na nossa usual heteronomia, comum a pacientes e trabalhadores, como seres que delineiam a lógica da realidade através da convivência social. Na atenção à Saúde Mental, são os pacientes que, "no limite das suas necessidades, têm inscrito, nas instituições sociais, o conjunto dos seus possíveis" (Sanduvette, 1997). Aos(às) trabalhadores(as) está delegada, nos CAPS, a responsabilidade - e, espera-se, a responsabilização - pela administração de grande parte dos possíveis e dos contingentes dos pacientes, através da construção, da (re)construção e da avaliação de projetos terapêuticos. Cada CAPS, à moda de uma pequena embarcação, porque dotado de estrutura organizacional simples e flexível, pode realizar manobras rápidas e adequadas ao leito do rio onde navega (seja o Amazonas ou o Chuí), com o cuidado que as diferentes ambiências demandam (como, aliás, não poderia deixar de ser). O Programa dos Centros de Atenção Psicossocial, no entanto, em nível nacional, tem dimensões transatlânticas: para mantê-lo depende-se da cartografia que está sendo construída (leia-se registros, avaliações, resolutividade, consolidação dos projetos de trabalho), com a ajuda dos(as) timoneiros(as) das centenas de pequenas embarcações.

Sanduvette, V. (2007). About how and why to construct, (re)construct and evaluate therapeutic projects in the Psychosocial Attention Centres (CAPS). Psicologia USP, 18(1), 83-100.

\begin{abstract}
The workers implied in the Brazilian Psychiatric Reform, predominantly women, have been facing the challenge of transforming the ways in which people who suffer from mental health problems are treated. For this endeavor it is necessary to count on operators for the reorganization of the work, moving from carrying out tasks to projects and from multidisciplinarity to interdisciplinarity. With this purpose, we have applied a method of analysis and intervention based on records of personal staff reports about social interactions, from which "pictures"
\end{abstract}


Sobre Como e Por Que Construir, (Re)Construir e Avaliar Projetos Terapêticos...

of the routines of assistance are constructed and are subsequently transformed into protocols for psychosocial observation and evaluation. The evaluations constitute an axis in information management and are seen as fundamental to Collective Health practices in Public Health. We emphasize the importance of the reinvention of therapeutic actions on the daily routines of the communitarian services associated with the Mental Health Model of Psychosocial Attention and Rehabilitation.

Index terms: Psychiatric Reform (Brazil). Psychosocial rehabilitation. Work organization. Ethnomethodology. Interdisciplinarity. Public health.

Sanduvette, V. (2007). Sur comment et pourquoi construir, (re)construir et évaluer des projets thérapeutiques aux Centres de Rehabilitation Psychosocial (CAPS). Psicologia USP, 18(1), 83-100.

Résumé: En soulignant que la majorité des acteurs de la réforme psychiatrique du Brasil est constituée par des femmes et que son grand défi consiste surtout a transformer la façon dont les souffrants sont traités, cet article met en relief que ses efforts doivent compter sur l'organisation du travail, y comprises les actions ordinaires et l'élaboration des projets majeurs, ce qui implique un changement de la visée multidisciplinaire à l'interdisciplinaire. On a enregistré des rapports sur les routines entendues comme des protocoles d'observation des patients e d'évaluation psychosociale, et la gestion de l'information, principe fondamental des pratiques dans le domaine de la santé publique, est donc abordée de façon que l'on puisse comprendre l'importance de la réinvention des actions thérapeutiques pour que les routines quotidiennes des services communautaires soient basées sur l'attention psychosociale et la réhabilitation, ainsi que déterminées par une politique publique.

Mots clés: Réforme psychiatrique (Brasil). Réhabilitation psychosocial. Organisation du travail. Ethnométhodologie. Interdisciplinarité. Santé publique. 


\section{Verônica Sanduvette}

\section{Referências}

Almeida Filho, N. (2005). Transdisciplinaridade e o paradigma pós-disciplinar na saúde. Saúde e Sociedade, 14(3), 30-50.

Alvarenga, A. T., Sommerman, A., \& Álvares, A. M. S. (2005). Congressos internacionais sobre transdiciplinaridade: reflexões e convergências de idéias e ideais na direção de uma nova ciência moderna. Saúde e Sociedade, 14(3), 9-29.

Arendt, H. (1991). A condição humana (5a ed.). Rio de Janeiro: Forense.

Arendt, H. (2004). Julgamento e responsabilidade. São Paulo: Companhia das Letras.

Assessoria de Comunicação Social da Secretaria de Estado da Saúde de São Paulo. (2004, março). Jornal São Paulo Saúde.

Barthes, R. (2005). A câmara clara. São Paulo: Edições 70.

Berger, P. I., \& Luckmann, T. (1996). A construção social da realidade. Petrópolis, RJ: Vozes.

Bosi, E. (2004). O tempo vivo da memória (2a ed.). São Paulo: Ateliê Editorial.

Castiels, L. D. (1999). A medida do possível... saúde, risco e tecnobiociências. Rio de Janeiro: Contra Capa.

Chanlat, J. P. (1997). Modos de gestão, saúde e segurança no trabalho. In E. Davel \& J. Vasconcelos (Orgs.), Recursos humanos e subjetividade. Petrópolis, RJ: Vozes.

Conselho Regional de Psicologia, 6. (1997). Trancar não é tratar. Liberdade: o melhor remédio (2a ed.). São Paulo: Autor.

Declaração de Caracas. (2004). In Ministério da Saúde. Secretaria-Executiva. Secretaria de Atenção à Saúde Legislação em Saúde Mental 1990-2004 (5a ed., pp. 11-13). Brasília, DF: Autor. (Declaração publicada em 14 de novembro de 1990)

Enriquez, E. (1997a). O indivíduo preso na armadilha da gestão estratégica. Revista de Administração de Empresas, FGV, 37(1), 19-29.

Enriquez, E. (1997b). A organização em análise. Petrópolis, RJ: Vozes.

Ferreira, A. B. H. (1975). Dicionário da Língua Portuguesa. Rio de Janeiro: Nova Fronteira.

Garfinkel, H. (1984). Studies in ethnometodology. Cambridge: Polity Press.

Guba, E. G., \& Lincoln, Y. S. (1989). Fourth generation evaluation. Newbury Park, CA: Sage.

Heritage, J. C. (1999). Etnometodologia. In A. Giddens \& J. Turner (Orgs.), Teoria social hoje. São Paulo: Ed. Unesp. 
Sobre Como e Por Que Construir, (Re)Construir e Avaliar Projetos Terapêuticos...

Malvezzi, S. (1994). Do taylorismo ao comportamentalismo - 90 anos de desenvolvimento de recursos humanos. In G. V. Boog, Manual de treinamento e desenvolvimento (2a ed., cap. 12, pp. 15-32). São Paulo: Makron Books.

Malvezzi, S. (1996). Da gestão da informação para a gestão do conhecimento: o novo paradigma da gestão de empresas. Revista de Marketing Industrial, 1(3), 5359.

Merhy, E. E, Magalhães Junior, H. M., Rimoli, J., Franco, T. B., \& Bueno, W. S. (2004). (Orgs.), O trabalho em saúde: olhando e experienciando o SUS no cotidiano (2a ed.). São Paulo: Hucitec.

Ministério da Saúde. Secretaria de Atenção à Saúde- DAPE. (2007). Saúde mental no SUS: acesso ao tratamento e mudança no modelo de atenção. Relatório de Gestão, 20032006. Brasília, DF: Autor.

Morin, E. (1990). Introdução ao pensamento complexo. Lisboa: Instituto Piaget.

Morin, E. (1996). Ciência com consciência. Rio de Janeiro: Bertrand Brasil.

Morin, E. (2003). Os sete saberes necessários à educação do futuro. São Paulo: Cortez.

Livet, P. (1981). Temps de travail, acte reflexive, force productive. Revue de Metaphisique et de Morale, 86, 54.

Onocko Campos, R. (2001, maio/agosto). Clínica: a palavra negada - sobre as práticas clínicas nos serviços substitutivos de Saúde Mental. Saúde em Debate, Revista do Centro Brasileiro de Estudos de Saúde, 25(58).

Oury, J. (1986). Séminaire de Sainte-Anne. Le colletif. Paris: Maspéro.

Piaget, J. (1986). O possível e o necessário (Vol. 1). Porto Alegre: Artes Médicas.

Pitta, A. M. F. (1996). Reabilitação psicossocial no Brasil. São Paulo: Hucitec.

Psicologia usa batom. (2006). Jornal do Conselho Federal de Psicologia, 19(84), 14.

Sanduvette, V. (1997). Avaliação psicológica nas instituições: análise das rotinas de interação social de um hospital psiquiátrico através de relatos escritos. Dissertação de Mestrado, Instituto de Psicologia, Universidade de São Paulo.

Sanduvette, V. (2001). "Desinstitucionalizar” também é uma questão de gerenciamento. In Conferência Nacional de Saúde Mental, III: cuidar sim, excluir não. Caderno de Textos. Brasília: Ministério da Saúde. Conselho Nacional de Saúde.

Sanduvette, V. (2003). Organização do trabalho e rotinas em Saúde Mental: conhecimento e mudança. Tese de Doutorado, Instituto de Psicologia, Universidade de São Paulo.

Saraceno, B. (1999). Libertando identidades. Da reabilitação psicossocial à cidadania possível. Belo Horizonte: Te Cora. 


\section{Verônica Sanduvette}

Saraceno, B. (2006). Global mental health challenges in a WHO perspective. In Congress of Psychosocial Rehabilitation, IX - Book of Abstracts (p. 14). Atenas.

Schütz, A. (1976). The social world and the theory of social action. In Collect papers (Vol. 2). The Hauge: Martinus Nijhof.

Sommerman, A. (2006). Inter ou transdisciplinaridade. São Paulo: Paulus.

Spink, M. J. (Org.). (1999). Práticas discursivas e produção de sentidos no cotidiano: aproximações teóricas e metodológicas. São Paulo: Cortez.

Spink, P. (2003). Pesquisa de campo em Psicologia Social: uma perspectiva pósconstrucionista. Psicologia e Sociedade, 15(2), 18-42.

Vasconcelos, E. M. (1997). Desinstitucionalização e interdisciplinaridade em Saúde Mental. Cadernos IPUB, 1(7), 19-42.

Vertzman, J. S., \& Gutman, G. (1997). A clínica dos espaços coletivos e as psicoses. Cadernos IPUB, 1(7), 30-72.

Weick, K. (1989). Enactment and the boundaryless carrer: Organizing as we work. In The boundaryless carrer: A new organization era. s.l: s.n.

Recebido em: 25/07/2006

Aceito em: 11/09/2007 